\title{
Physiological Electromyographic Activation Patterns of Trunk Muscles During Walking
}

\author{
Matteo Cioni*, Mariangela Pisasale, Salvatore Abela, Tiziana Belfiore and Marco Micale
}

Gait and Motion Analysis Laboratory, Physical Medicine and Rehabilitation, School of Medicine, University of Catania, Italy

\begin{abstract}
It is well known that, in spite of its crucial role in the posture, locomotion and voluntary movements, trunk has received less consideration from researchers than upper and lower limbs. On the other hand, rehabilitative interventions of patients with upper motoneuron syndrome have always been focused firstly on treatment and recovery of trunk's posture during standing, sitting and walking.

Trunk is a complex anatomical structure and it is composed by a large variety of bones, articulations, ligaments and muscles. From a functional point of view, trunk muscles have been subdivided into two systems: a local system which ensures stability and a global system which enables movements. Muscles of these two systems work by eccentric and concentric contractions, according to the functional needs.

Surprisingly, in the literature are reported only a few studies regarding the trunk muscle activations during walking. These studies investigated the electromyographic activation patterns in different experimental conditions as walking on a walkway, over a treadmill at different velocities, in water or in deep-water. Furthermore, data analysis was differently performed by analyzing the qualitative and quantitative features of timing and amplitude of electromyographic recordings for each muscle or by other more sophisticated methods as cluster analysis or principal components analysis. Finally, some variability has been observed in the normal population also including sex differences. The aim of this review is to show the state of art of this topic, in normal subjects.
\end{abstract}

Keywords: Surface electromyography, trunk, muscle, gait, anatomy.

\section{INTRODUCTION}

Rehabilitation interventions both in children and adults with upper motoneuron syndrome are firstly focused on the recovery of trunk control during sitting, standing and walking. In fact, rehabilitation concepts, methods and techniques are in most of cases focused to get firstly trunk "stability" and secondly the control of limb movements. In paediatric rehabilitation, for example, the control of trunk is one of the pre-requirements to the following developmental stages and, in the adult with stroke, the Trunk Control Test [1] is an useful tool to make a functional prognosis of recovery. In spite of this clinical interest, only a limited information is available in the literature regarding the muscle activation patterns of trunk during walking, both in normal and pathological subjects. Then, the aim of this review is to show the state of art of this topic, with a particular focus on the electromyographic muscle activation patterns recorded by surface electrodes during walking, in normal subjects.

\section{TRUNK ANATOMY}

Trunk is an anatomical structure consisting of neck, thorax, abdomen and pelvis. It contains and protects the vital organs of the body and by the spine connects the head with the pelvis and both scapular and pelvic girdles. The spine has

*Address correspondence to this author at the Gait and Motion Laboratory, Physical Medicine \& Rehabilitation, School of Medicine, University of Catania, Catania, Italy; Tel: +39 95 7384079; Fax: +39 95 7384238;

E-mail: cioni.matteo@gmail.com four physiological bends, sacral and dorsal bends with a front concavity, while lumbar and cervical bends have a back concavity. During phylogenesis, the passage from a quadruped position to a bipedal position firstly caused a straightening and then an inversion of the lumbar bend, initially with a frontal concavity. Also, the spine undergoes a progressive modelling during the ontogenetic development. Some authors [2] have shown that the foetus spine has only one curvature from cranial to caudal. After birth, the first day of life, spine shows a marked lumbar lordosis, which is progressively reduced at five months and it is substituted by a straight spine at thirteen months [3]. The spine's lordosis develops progressively from the age of three years throughout eight years, and reaches a final development in the childhood (about 10 years of age) [2]. The presence of spine bends has a great functional meaning due to the fact that they increase the resistance of spine to axial stress.

In Table 1, are reported the main superficial and deep muscles of the trunk (neck, thorax, back-abdominal wall and pelvis) involved in the posture, voluntary movements as well as in breathing.

Classical histological work, performed by Thorstensson and Carlson [4] has firstly shown a prevalence of type I fibres (slow twitch) in multifidus and erector spinae. This information has been confirmed and extended by Mannion and coll. [5] in normal subjects without low back pain, by investigating the histological characteristics of muscle fibres in two different anatomical regions (thoracic and lumbar) of erector spinae. They [5] found a predominance of type I muscle fibres, without regional differences and reported that 
Table 1. Main Muscles of Trunk

\begin{tabular}{|c|c|c|c|c|c|}
\hline $\begin{array}{l}\text { Back } \\
\text { Trunk }\end{array}$ & & $\begin{array}{l}\text { splenius } \\
\text { (capitis, } \\
\underline{\text { cervicis })}\end{array}$ & $\begin{array}{l}\begin{array}{l}\text { erector } \\
\text { (iliocostalis, }\end{array} \\
\underline{\text { spinalis) }}\end{array}$ & $\begin{array}{l}\text { transversospinales: (semispinalis dorsi, } \\
\text { cervicis, semispinalis capitis, }, \underline{\text { multifidus }}, \underline{\text { rotatores })} \\
\underline{\text { interspinales }} \\
\underline{\text { intertransversarii }}\end{array}$ & $\begin{array}{l}\left.\frac{\text { latissimus dorsi }}{\text { (major, }} \cdot \underline{\text { minor }}\right) \cdot \frac{\text { rhomboid }}{\text { levator }} \\
\underline{\text { scapulae }}\end{array}$ \\
\hline Thorax & & \multicolumn{4}{|c|}{$\begin{array}{l}\text { intercostales (external, internal, innermost), subcostales, transversus thoracis, levatores costarum, serratus posterior (inferior, } \\
\underline{\text { superior), diaphram }}\end{array}$} \\
\hline & & \multicolumn{4}{|c|}{ pectoralis major $\cdot$ pectoralis minor $\cdot$ subclavius $\cdot$ serratus anterior } \\
\hline & & \multicolumn{4}{|c|}{ fascia: pectoral fascia $\cdot$ clavipectoral fascia } \\
\hline \multirow[t]{2}{*}{$\begin{array}{l}\text { Abdomen } \\
\text { Wall }\end{array}$} & $\begin{array}{l}\text { Anterior } \\
\text { Lateral }\end{array}$ & \multicolumn{4}{|c|}{$\begin{array}{l}\text { transversus abdominis/conjoint tendon, rectus sheath (rectus abdominis, pyramidalis) } \\
\text { abdominal internal oblique, abdominal external oblique, }\end{array}$} \\
\hline & Posterior & \multicolumn{4}{|c|}{ quadratus lumborum, psoas major/psoas minor, iliacus, iliopsoas fascia (iliac fascia/iliopectineal arch) } \\
\hline Pelvis & & \multicolumn{4}{|c|}{$\begin{array}{l}\text { rectus femoris } \\
\text { gluteus maximus, gluteus medius }\end{array}$} \\
\hline
\end{tabular}

in men type I fibres are greater in diameter than in women. In the same line of evidence, they showed that in females, differently from males, type I fibres are larger in diameter than type II. Thus, these authors suggested that these morphological differences could be the expression of adaptive responses to differences in function. Furthermore, they concluded that possible differences in the diameters of muscle fibres should be considered carefully, in order to differentiate "atrophied" cells from physiologically "smaller" cells. Histochemical muscle fibre composition of abdominal muscles has been studied by Haggmark and Thorstensson [6]. These authors showed the presence of type I, II A, II B or II C muscle fibres, with large inter-individual variations in fibre composition. On the other hand, abdominal muscles, in the same subject, appear to have similar histochemical features and functional capacity.

From a kinesiological point of view, trunk muscles are divided into two systems: a local system which ensures stability and a global system which enables movements [7, 8]. The muscles of the local system are permanently active at low levels, independently from movements, whereas the muscles of the global system act to initiate movements dependent on phasic activation patterns $[8,9]$. More recently, the global system was divided into two other sub-systems: the global stabilizing and the global mobilizing [9, 10]. The first sub-system (stabilizer) controls and limits movements by means of eccentric activations and in this regards it is complementary to the activity of the local system. The second sub-system (mobilizer) initiates movements by phasic activations of related muscles. As described by Comerford and Mottram [9] stabilizer muscles are monoarticular, have segmental attachments and when superficial they have broad aponeurotic insertions to distribute load and forces. On the other hand, mobilizer muscles are bi-articular/multiarticular, superficial, with long levers, large moment arms and greatest bulks. Moreover, these authors [9] described the characteristics of local and global muscles. The former, which are the deepest muscles, originate and insert at each segment of rachis. Also, they control and maintain the neutral spinal curvature, respond to changes in posture and in low extrinsic load, work independently from the direction of load or movement and appear to be biased for load activity.
The latter, the superficial or outer layer muscles, insert or originate on the thorax or pelvis (non-segmentally), respond to changes in the line of action and to the magnitude of high extrinsic load by producing large torques. Muscles multifidus, semispinalis cervicis, subscapularis are stabilizers, whereas latissimus dorsi, rectus femoris, sterno cleidomastoideus and rectus abdominis are mobilizers. In this regard, Figs. $(\mathbf{1}, \mathbf{2})$ show the echographic recordings of some low back muscles at L1 and L4 levels, in the transversal plane. At L1 (Fig. 1), it is possible to see the multifidus and lumbar erector spinae divided by an aponeurotic lamina, whereas at L4 (Fig. 2) we can see multifidus and longissimus dorsi.

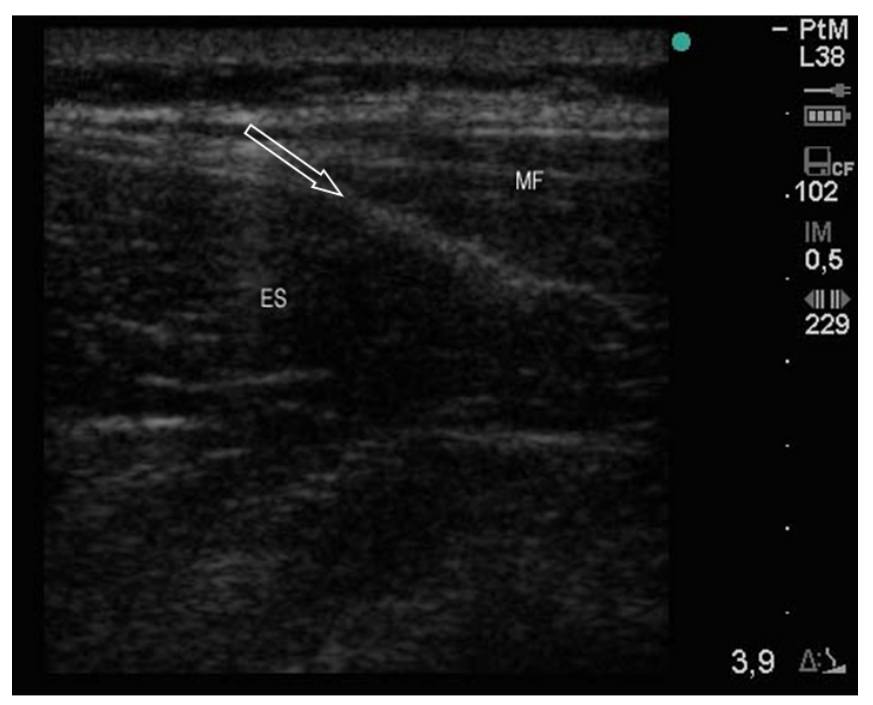

Fig. (1). This figure shows, in the transversal plane, multifidus (MF) and erector spinae (ES) muscles on the left side of a young subject, at level of L1. These muscles are divided by an aponeurotic lamina (arrow).

\section{PHYSIOLOGICAL ACTIVATION PATTERNS OF TRUNK MUSCLES}

By considering the complex architecture of trunk muscles, a crucial point to have realistic recordings is the 


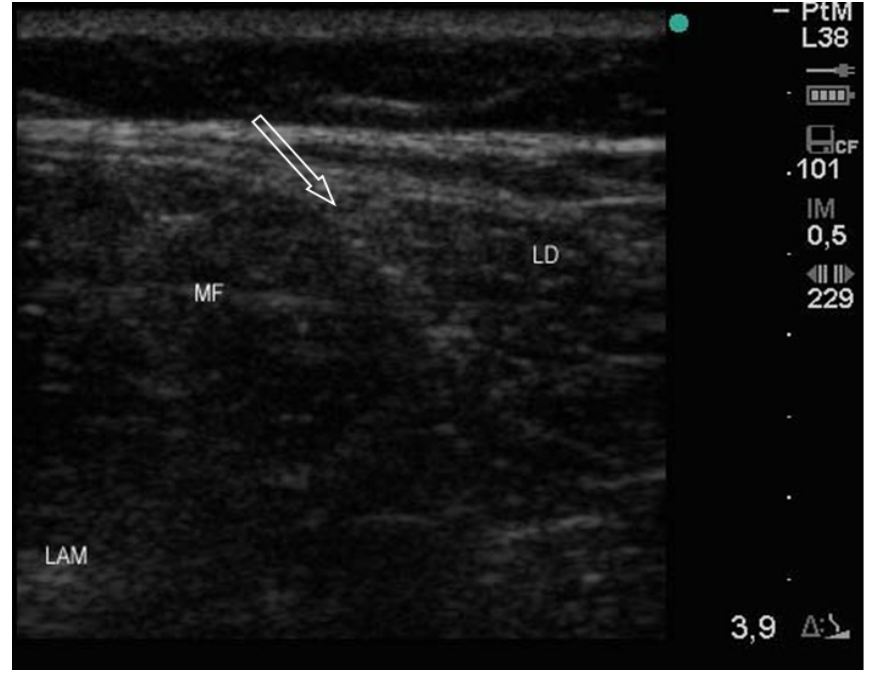

Fig. (2). This figure shows, in the transversal plane, multifidus (MF) and longissimus dorsi (LD ) muscles on the left side of a young subject, at level of L4.

anatomical location where skin electrodes are positioned. In Tables 2-5 are reported anatomical locations of electromyographic surface electrodes reported in several experimental studies investigating trunk activation patterns during walking. As can be seen, there are some differences in the anatomical locations for the most investigated muscles (erector spinae, obliquus externus abdominis, obliquus internus abdominis and rectus abdominis) which could affect the comparison of data between these studies. An interesting anatomical-physiological study of de Sèze and Cazalets [11] has attempted to optimize the anatomical location of electromyographic surface electrodes by dissecting trunks of 20 cadavers and by identifying the more superficial anatomical points where to place surface electrodes. Then, they proposed an interesting protocol to record the electromyographic activity of erector spinae through the superficial aponeurosis. The efficacy of this anatomical protocol was further confirmed by electromyographic recordings of muscle activation patterns from 4 regions of erector spinae, in five healthy subjects.

The classical book of J. Perry [12] reports muscle activation patterns of trunk muscles during walking, recorded by surface electromyography. She observed that the activity of pelvic abductor muscles (upper gluteus maximus and gluteus medius), starts in the late terminal swing (95\% of gait cycle), it is prolonged throughout the mid stance (24 $\%$ of gait cycle) and reaches a peak during the loading response (4-8\%) of gait cycle.

Table 2. Anatomical Locations of Electrodes Over m. Erector Spinae

\begin{tabular}{|c|c|}
\hline Authors & Muscle Erector Spinae \\
\hline $\begin{array}{l}\text { de Seze and Cazalets Jr [11] } \\
\text { (5 healthy subjects) }\end{array}$ & $\begin{array}{l}\text { After making two points, } 2 \text { and } 4 \mathrm{~cm} \text { laterally from the spinous process at C7 and L4, respectively the points are } \\
\text { joined by a line and the electrodes are placed on it at each spine level. T3 were located at level of the medial angle } \\
\text { of the scapulae. T12 electrodes were located at the level of iliac crest. }\end{array}$ \\
\hline $\begin{array}{l}\text { Winter [13] } \\
\text { (16 healthy young subjects) }\end{array}$ & $2 \mathrm{~cm}$ lateral to the spinous process at level of the iliac crest. \\
\hline $\begin{array}{l}\text { Anders et al. }[14] \\
\text { (15 healthy males, } 24-35 \text { yrs) }\end{array}$ & Longissimus: over palpable bulge of muscle (approx $3 \mathrm{~cm}$ lateral midline) lower electrode at L1 level, vertical. \\
\hline $\begin{array}{l}\text { Ceccato et al. }[16] \\
(9 \text { healthy males, } 27 \pm \underline{6} \text { yrs })\end{array}$ & $\begin{array}{l}\text { After making two points, } 2 \text { and } 4 \mathrm{~cm} \text { laterally from the spinous process at C7 and L4, respectively the points are } \\
\text { joined by a line and the electrodes are placed on it at each spine level. T3 were located at level of the medial angle } \\
\text { of the scapulae. T12 electrodes were located at the level of iliac crest. }\end{array}$ \\
\hline $\begin{array}{l}\text { White and Mcnair [19] } \\
\text { (38 adult subjects, } 19 \text { males and } 19 \\
\text { females, } 26 . \pm 6.5 \text { yrs) }\end{array}$ & Lumbar erector spinae: L4-L5 interspace, $2 \mathrm{~cm}$ lateral to the midline. \\
\hline $\begin{array}{l}\text { Ivanenko et al.[20] } \\
\text { (13 healthy young males) }\end{array}$ & $2 \mathrm{~cm}$ laterally to the spinous process of $\mathrm{L} 2, \mathrm{~T} 1$ and $\mathrm{T} 9$. \\
\hline $\begin{array}{l}\text { Kaneda et al. }[21] \\
\text { (9 healthy young males, } 25.1 \pm 2.3 \\
\text { yrs) }\end{array}$ & Lumbar erector spinae: "the position of L2". \\
\hline $\begin{array}{l}\text { Callaghan }[25] \\
(5 \text { males subjects, } 25 \pm 2.8 \text { yrs })\end{array}$ & $\begin{array}{l}\text { Thoracic erector spinae: } 5 \mathrm{~cm} \text { lateral to spinous process. } \\
\text { Lumbar erector spinae: } 3 \mathrm{~cm} \text { lateral to } \mathrm{L} 3 \text { spinous process. }\end{array}$ \\
\hline $\begin{array}{l}\text { Barton et al., } 2008[26] \\
(15 \text { healthy young females, } 20.7 \\
\pm 0.9 \text { yrs })\end{array}$ & $\begin{array}{l}\text { Lumbar erector spinae: "one electrode was placed } 3 \mathrm{~cm} \text { lateral to the } \mathrm{L} 4 \text { spinous process and another directly above } \\
\text { it". }\end{array}$ \\
\hline $\begin{array}{l}\text { Saunders et al. }[27] \\
\text { ( } 7 \text { healthy subjects, } 6 \text { males and } 1 \\
\text { female) }\end{array}$ & $4 \mathrm{~cm}$ lateral to the midline at $\mathrm{L} 2$. \\
\hline $\begin{array}{l}\text { Bird et al. }[28] \\
\text { (13 healthy young females and } \\
\text { males, } 22.3+3.4 \text { yrs })\end{array}$ & $\begin{array}{l}\text { Lumbar erector spinae: "3 } \mathrm{cm} \text { lateral to spinous process of L3. One electrode in this point and another directly } \\
\text { above." }\end{array}$ \\
\hline
\end{tabular}


Table 3. Anatomical Locations of Electrodes Over m. Rectus Abdominis

\begin{tabular}{|l|l|}
\hline \multicolumn{1}{|c|}{ Authors } & \multicolumn{1}{c|}{ Muscle Rectus Abdominis } \\
\hline \hline $\begin{array}{l}\text { Anders } \text { et al. }[14] \\
(15 \text { healthy males, } 24-35 \mathrm{yrs})\end{array}$ & $4 \mathrm{~cm}$ lateral navel, lower electrode at navel level, vertical. \\
\hline $\begin{array}{l}\text { White and Mcnair [19] } \\
(38 \text { adult subjects, } 19 \text { males and } 19 \text { females, } 26.0 \pm 6.5 \mathrm{yrs})\end{array}$ & At the level of the anterior superior iliac spine, $2 \mathrm{~cm}$ lateral to the midline. \\
\hline $\begin{array}{l}\text { Ivanenko } \text { et al. }[20] \\
(13 \text { healthy young males })\end{array}$ & $3 \mathrm{~cm}$ lateral to umbelicus. \\
\hline $\begin{array}{l}\text { Kaneda } \text { et al. }[21] \\
(9 \text { healthy young males, } 25.1 \pm 2.3 \mathrm{yrs})\end{array}$ & "the position of T11". \\
\hline $\begin{array}{l}\text { Saunders } \text { et al. }[27] \\
(7 \text { healthy subjects, } 6 \text { males and } 1 \mathrm{female})\end{array}$ & Line drawn between right and left superior iliac spine, $2 \mathrm{~cm}$ lateral to umbilicus. \\
\hline
\end{tabular}

Table 4. Anatomical Locations of Electrodes Over m. Obliquus Externus Abdominis

\begin{tabular}{|l|l|}
\hline \multicolumn{1}{|c|}{ Authors } & \multicolumn{1}{|c|}{ Muscle Obliquus Externus Abdominis } \\
\hline \hline $\begin{array}{l}\text { Anders } \text { et al. }[14] \\
(15 \text { healthy males, } 24-35 \mathrm{yrs})\end{array}$ & Upper electrode directly below most inferior point of costal margin, on line to opposite pubic tubercle. \\
\hline $\begin{array}{l}\text { White and Mcnair }[19] \\
(38 \text { adult subjects, } 26.0 \pm 6.5 \mathrm{yrs})\end{array}$ & Just below the rib cage at the inferior angle of the ribs. \\
\hline $\begin{array}{l}\text { Kaneda } \text { et al. }[21] \\
(9 \text { healthy young males, } 25.1 \pm 2.3 \mathrm{yrs})\end{array}$ & "Right above of midpoint between the top of iliac spine and the anterior superior iliac spine". \\
\hline $\begin{array}{l}\text { Sung } \text { et al. }[24] \\
(7 \text { healthy subjects and } 7 \text { adult individuals } \\
\text { with chronic post-stroke })\end{array}$ & "approximatively 15 cm lateral to the umbilicus". \\
\hline $\begin{array}{l}\text { Barton } \text { et al., } 2008[26] \\
(15 \text { healthy young females, } 20.7 \pm 0.9 \text { yrs })\end{array}$ & Just below the most inferior aspect of the coastal margin in line with the contralateral pubic tubercle. \\
\hline
\end{tabular}

Table 5. Anatomical Locations of Electrodes Over m. Obliquus Internus Abdominis

\begin{tabular}{|l|l|}
\hline \multicolumn{1}{|c|}{ Authors } & \multicolumn{1}{c|}{ Muscle Obliquus Internus Abdominis } \\
\hline \hline $\begin{array}{l}\text { Anders } \text { et al. }[14] \\
(15 \text { healthy males, } 24-35 \mathrm{yrs})\end{array}$ & Along horizontal line between both ASISs, medial from inguinal ligament. \\
\hline $\begin{array}{l}\text { White and Mcnair [19] } \\
(38 \text { adult subjects, } 19 \text { males and } 19 \text { females, } \\
26 . \pm 6.5 \mathrm{yrs})\end{array}$ & $\begin{array}{l}2 \mathrm{~cm} \text { inferior to a line joining the left and right anterior superior iliac spines, medial to the inguinal } \\
\text { ligament, but lateral to the lateral border of the rectus sheath. }\end{array}$ \\
$\begin{array}{l}\text { Barton } \text { et al., } 2008[26] \\
(15 \text { healthy young females, } 20.7 \pm 0.9 \mathrm{yrs})\end{array}$ & $1 \mathrm{~cm}$ inferior medially to th lelft anterior superior iliac spine (ASIS) in line with the right ASIS. \\
\hline
\end{tabular}

Erector spinae, which can be considered the main muscle of back is maximally active at about the $50 \%$ of gait cycle, corresponding to the heel contact of the contralateral limb. This muscle is active from the $40 \%$ of gait cycle, peaks at the $50 \%$, and continue to be active throughout the pre-swing. On the other hand, according to Winter [13] this muscle has two peaks of activity: the first at $10 \%$ and the second at the $60 \%$ of gait cycle. The multifidus is active in both sides at the heel contact and it is extended from the $90 \%$ to the $12 \%$ of gait cycle of the ipsilateral limb. The rectus abdominis shows a low continuous activity throughout the whole gait cycle. On the contrary, obliquus internus abdominis and obliquus externus abdominis show an intermittent activity with some low peaks of activity during late mid swing and early terminal swing (75-90 \%). In Fig. (3) are reported activation patterns of trunk muscles in a normal young subject, during walking at moderate velocity.

The influence of velocity on activation patterns of trunk muscles during walking over a treadmill has been recently investigated by Anders et al. [14]. These authors reported that the cumulative amplitude of all investigated muscles increased with gait velocity. However, a more in depth analysis showed that the amplitude levels of rectus abdominis were not modified by velocity, whereas those of 

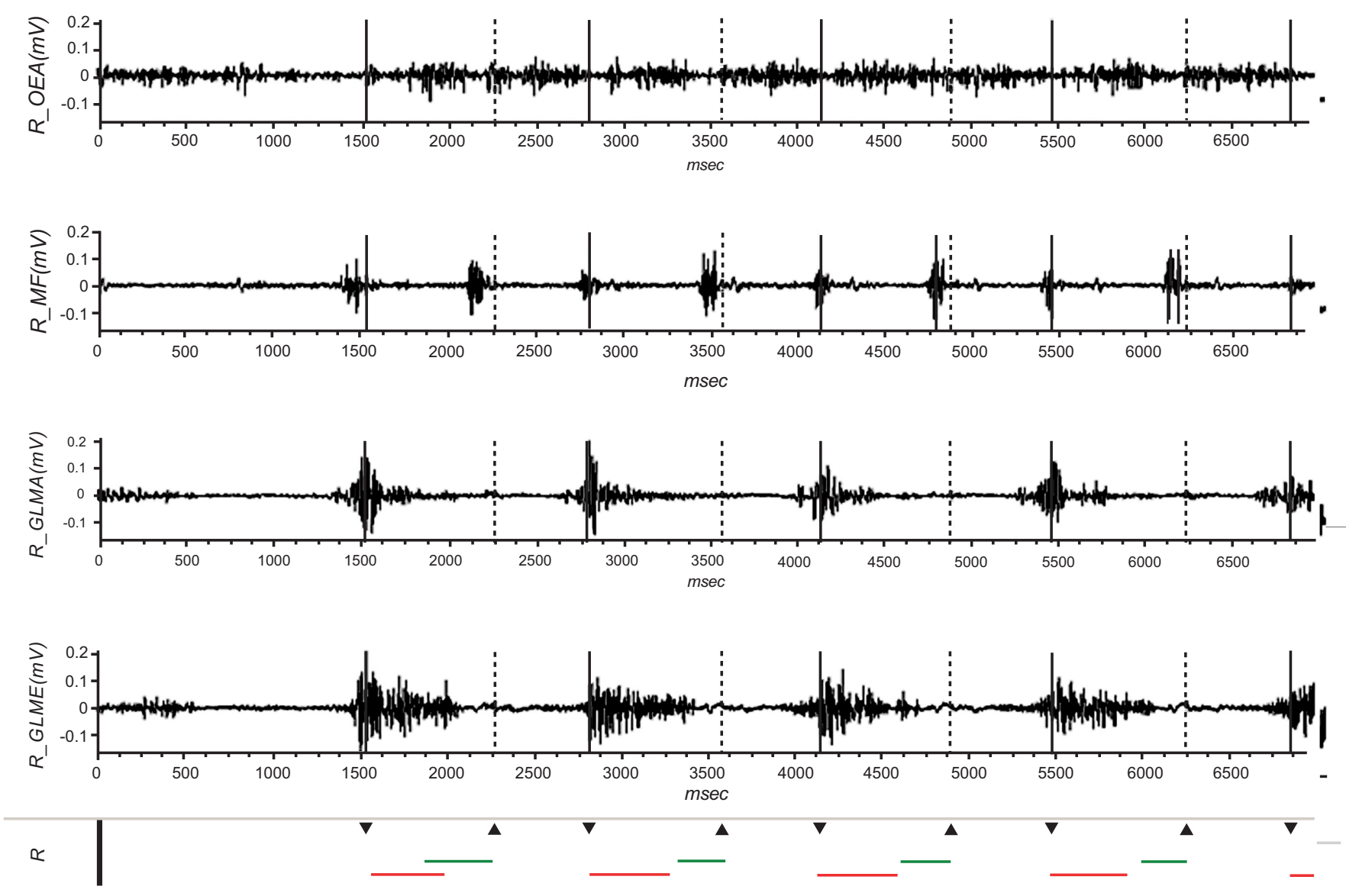

Fig. (3). In this figure are reported electromyographic recordings from four muscles of trunk of a normal young subject: obliquus externus abdominis, multifidus, gluteus maximus and gluteus medius. It can be seen that obliquus externus (OEA) shows a quite continuous activity with some peaks of activity, mainly during stance phase; the multifidus (MF) shows two peaks of activity at the ipsilateral heel strike and at about the $50 \%$ of cycle (corresponding to the heel strike of the contralateral foot): the gluteus maximus (GLMA)and medius (GLME) are active at the beginning and at the end of gait cycle.

erector spinae, multifidus, obliquus internus and externus were markedly increased by this gait parameter. Moreover, they [14] showed that erector spinae and multifidus, during walking over a treadmill, had some slight differences in respect to the activation patterns reported by Perry [12]. In fact, multifidus was active at both heel contacts (ipsilateral and contralateral side) whereas erector spinae was active only during the contralateral contact. These authors showed that activation patterns of obliquus externus abdominis and those of obliquus internus abdominis shared some similar aspects, but even some distinct differences. In fact, they showed that these muscles were mainly activated during the contra-lateral phase of propulsion, but some specific peaks of activity were observed for obliquus internus abdominis during the ipsilateral heel and pad contact, and for obliquus externus abdominis during the contralateral heel and pad contact. From the analysis of peak amplitudes, they concluded that obliquus externus abdominis and multifidus were eccentrically activated during the contralateral heel contact. Regarding to erector spinae, they reported that its peak of amplitude during the contralateral heel contact was related to an eccentric contraction to control the movement of spine and load transfer towards the lumbar region, as suggested by other authors [15]. A main functional role in the control of trunk has been further emphasized for the erector spinae by Ceccato and coll. [16]. In fact, these authors compared its activation patterns at the initiation of gait and during walking and identified metachronal descending patterns in both activities, with a double burst of activity not only at lumbar level as reported by other authors $[14,17,18]$ but more interestingly at each spinal level during walking. Furthermore, they also reported [16] that one of these bursts propagates rostro-caudally (from C7 to L3).

In order to identify the possible variations in both patterns and amplitude of electromyographic activity of trunk muscles, a different methodological study [19] was performed by a cluster analysis of abdominal and erector spinae muscle activity during gait, in a large group of normal adult subjects. Interestingly, this study [19] identified the presence of two patterns of activity for obliquus internus abdominis, obliquus externus abdominis and rectus abdominis and of three patterns of activity for lumbar erector spinae. In fact, the authors showed that obliquus internus abdominis has a relatively constant low level activity in most of subjects investigated (64\%) and a biphasic pattern of activity, with maximum values occurring during mid to late stance phase of each leg, in the $36 \%$ of subjects. Regarding the obliquus externus abdominis, this 
muscle showed a prolonged low activity throughout the gait cycle in the $81 \%$ of subjects, and a biphasic pattern, with peaks of activity occurring close to the foot-strike, in the other $19 \%$ of subjects. In the same line of evidence, rectus abdominis showed very low levels of activity during the gait cycle in the $87 \%$ of subjects, whereas in the remaining $13 \%$ of subjects, it was observed a distinct biphasic pattern of activity with peaks occurring close to each foot-strike. The activity of erector spinae (recorded at L4/L5 $2 \mathrm{~cm}$ from midline) was characterized by three patterns of electromyographic activity all close to foot-strike.

Ivanenko et al. [20] performed an analysis of the principal components of the electromyographic activity of 16 muscles, by including some trunk muscles as gluteus maximus, erector spinae, rectus abdominis (superior) rectus abdominis (middle) obliquus externus abdominis, latissimus dorsi and trapezius, during walking of 13 subjects. These authors [20] have identified five basic muscle activation patterns accounting for a considerable fraction of the total electromyographic pattern of variance for most of recordable muscles, including trunk muscles. This observation pointed out that the Central Nervous System generates some basic patterns which are combined according to the specific needs to produce the observed muscle activations. Furthermore, these patterns are present independently from anthropometric characteristics, walking velocity and gravitational loads. It is interesting to note that whilst activation patterns of each muscle can vary according to the functional demand (e.g. increase of walking velocity) the basic electromyographic components show only limited changes. The authors [20] suggested firstly that a few oscillating circuits could drive the active muscles to produce the locomotion kinematics and secondly that a dynamic and flexible distribution of these basic components to the muscles could be driven by proprioceptive inputs and by descending volleys from the suprasegmental structures.

Water walking and deep water walking are physical activities well recognized both for fitness and rehabilitation. In order to study the activity of trunk muscle during waterexercise, Kaneda et al. [21] investigated the electromyographic activity of some trunk muscles (erector spinae, rectus abdominis, obliquus externus abdominis) during self determined low, moderate and fast paces. Interestingly, these authors [21] found that the electromyographic peaks of activation of erector spinae were absent during water walking and were substituted by a prolonged activation for most of the gait cycle. In the same experimental condition, both rectus abdominis and obliquus externus abdominis, showed very low levels of electromyographic activation. On the other hand, walking in deep water induced a marked and phasic electromyographic activity of all these muscles, indicating the dependence of these muscles on body inclinations occurring during walking in an unstable floating situation.

The influence of fatigue on electromyographic patterns during walking was explored by Olson [22]. This author recorded electromyographic patterns of lumbar paraspinalis, rectus abdominis, obliquus externus abdominis before and post sub-maximal trunk extensor efforts $(50 \%$ and $70 \%$ of a maximal trunk isometric extension effort). He found that a fatiguing exercise cause some temporal modifications of electromyographic recording. In fact, in the group of subjects involved in the most fatiguing task ( $70 \%$ of maximal effort) peaks of activity of lumbar paraspinalis and rectus abdominis shifted in time at the contralateral heel contact with a significant delay in the activation of rectus abdominis. Electromyographic recordings performed after an effort $50 \%$ of maximal effort, caused a modification of electromyographic timing of obliquus externus abdominis, whose peak of activation became closer to the heel strike of the contralateral leg.

It is well recognized that gait patterns of male and females are different and this is caused mainly by anthropometric differences as the hip architecture or height. Recently, Anders et al. [23] by analyzing the occurrence of sex-specific co-ordination patterns of some trunk muscles, found that they were different in males in respect to females. This phenomenon was more evident at velocities of walking higher than $4 \mathrm{~km} / \mathrm{h}$. The sex differences of muscle activation patterns did not include rectus abdominis which showed similar patterns in both sexes. Regarding to muscles obliquus externus and internus, both males and females showed respectively three-phasic and bi-phasic peaks of activation. According to these authors [23] obliquus externus exhibited larger amplitude peaks in females during ipsilateral pad contact and contra-lateral propulsion and it seems to be more prominently involved in females for active trunk rotation movements. On the other hand, obliquus internus exibited higher amplitudes in males. Since, the activity of this muscle seems to be related to an increase of trunk stability, the authors hypothesized that obliquus internus is more important for stabilization in man, whereas the obliquus externus in woman is more related to the mobilization of trunk. A further sex difference, was observed for erector spinae, because in females this muscle exhibited higher amplitudes during the contralateral heel contact, probably to be correlated to the large trunk movement occurring in sagittal plane in females.

\section{CONCLUSIONS}

The complexity of trunk muscle anatomy and physiology represents a challenge both for experimental researchers and clinicians, when they investigate patients with upper motoneuron syndrome. However, by using surface electromyography, it is possible to have some more specific information regarding to the spatial and temporal features of trunk superficial muscles and their correlation with gait parameters. Then, by this methodological approach, we can understand firstly if abnormalities of trunk movements depend on a specific neural deficit or if they are caused by secondary compensatory mechanisms to avoid loss of balance; secondly we can identify the presence of abnormal activations of mobilizer or stabilizer muscles. Consequently, by means of a more in depth evaluation, the rehabilitation approach can be oriented to more selective interventions.

\section{REFERENCES}

[1] Franchignoni FP, Tesio L, Tesio L, Ricupero C, Martino MT Trunk control test as early predictor of stroke rehabilitation out come. Stroke 1997; 28: 1382-5.

[2] Dimeglio A, Bonnel F. Le rachis en croissance. USA: Springer 1990.

[3] Abitbol MM. Evolution of the lumbosacral angle. Am J Phys Anthropol 1987; 72(3): 361-72. 
[4] Thorstensson A, Carlson H. Fibres types in human lumbar back muscles. Acta Physiol Scand 1987; 131: 195-202.

[5] Mannion AF, Dumas GA, Cooper RG, Espinosa FJ, Faris MW. Muscle fibre size and type distribution in thoracic and lumbar regions of erector spinae in healthy subjects without low back pain: normal values and sex differences. J Anat 1997; 190: 505-13.

[6] Haggmark T, Thorstensson A. Fibre types in human abdominal muscles. Acta Physiol Scand 1979; 107: 319-25.

[7] Goff B. The application of recent advances in neurophysiology to Miss Roods's concept of neuromuscular facilitation. Phys Ther 1972; 58(2): 409-15.

[8] Bergmark A. Stability of the lumbar spine. A study in mechanical engineering. Acta Orthop Scand Suppl 1989; 230: 1-54.

[9] Comerford MJ, Mottram SL. Movement and stability dysfunctioncontemporary developments. Man Ther 2001; 6 (1): 15-26.

[10] Gibbons SGT, Comerford MJ. Strength versus stability. Part 1: concept and terms. Orthop Div Rev 2001; 21-7.

[11] de Sèze MP, Cazalets JR. anatomical optimization of skin electrode placement to record electromyographic activity of erector spinae muscles. Surg Radiol Anat 2008; 30: 137-43.

[12] Perry J. Gait analysis: normal and pathological function. USA: SLACK Inc. 1992.

[13] Winter DA. Biomechanics of normal and pathological gait. Implications for understanding human locomotor control. J Mot Behav 1989; 21: 337-55.

[14] Anders C, Wagner H, Puta C, Grassne R, Petrovic A, Scholle HC. Trunk muscle activation patterns during walking at different speeds. J Electromyogr Kinesiol 2007; 17: 245-52.

[15] Vleeming A, Pool Goudzwaard Al, Stoeckart R, van Wingerden JP, Snijders CJ. The posterior layer of the thoracolumbar fascia. Its function in load transfer from spine to legs. Spine 1995; 20: 753-8.

[16] Ceccato JC, de Sèze M, Azevedo C, Cazalets JR. Comparison of trunk activity during gait initiation and walking in humans. PLoS One 2009; 4(12): e8193.
[17] Thorstensson A, Carlson H, Zomlefer MR, Nilsson J. Lumbar back muscle activity in realtion to trunk movements during locomotion in man. Acta Physiol Scand 1982; 116: 13-20.

[18] Saunders SW, Schache A, Rath D, Hodges PW. Changes in three dimensional lumbo-pelvis kinematics and trunk muscles activity with speed and mode of locomotion. Clin Biomech 2003; 20: 784.

[19] White S, McNair P. Abdominal and erector spinae muscle activity during gait: the use of cluster analysis to identify patterns of activity. Clin Biomech 2002; 17: 177-84.

[20] Ivanenko Y, Poppele RE, Laquaniti F. Five basic activation patterns account for muscle activity during human locomotion. J Physiol 2004; 556: 267-82.

[21] Kaneda K, Sato D, Wakabayashi, Nomura T. EMG activity of hip and trunk muscles during deep-water running. J Electromyogr Kinesiol 2009; 19: 1064-70.

[22] Olson MW. Trunk extensor fatigue influences trunk muscle activities during walking gait. J Electromyogr Kinesiol 2010; 20: 17-24.

[23] Anders C, Wagner H, Puta C, Grassne R, Scholle HC. Healthy humans use sex-specific co-ordination patterns of trunk muscles during gait. Eur J Appl Physiol 2009; 105: 585-94.

[24] Sung PS, Lee DC. Quantification of trunk muscle activation in subjects post-stroke using surface electromyography. J Electromyogr Kinesiol 2008 [Epub ahead of print].

[25] Callaghan JP, Patla AE, McGill SM. Low back three-dimensional joint forces, kinematics, and kinetics during walking. Clin Biomech (Bristol, Avon) 1999; 14: 203-216.

[26] Barton CJ, Coyle JA, Tinley P. The effect of heel lifts on trunk muscle activation during gait: a study of young healthy females. J Electromyogr Kinesiol 2008; 19(4): 598-606.

[27] Saunders SW, Rath D, Hodges PW. Postural and respiratory activation of the trunk muscles changes with mode and speed of locomotion. Gait Posture 2004; 20: 280-90.

[28] Bird AR, Bendrups AP, Payne CB. The effect of foot wedging on electromyographic activity in the erector spinae and gluteus medius muscles during walking. Gait Posture 2003; 18: 81-91. 